\title{
The Impact of Adverse Childhood Experiences on Coping Strategies in Schizophrenia Spectrum Disorders: A Case-Control Study
}

\author{
Justyna Kasznia' \\ Aleksandra Pytel ${ }^{2}$ \\ Bartłomiej Stańczykiewicz ${ }^{2}$ \\ Jerzy Samochowiec ${ }^{3}$ \\ Katarzyna Waszczuk ${ }^{3}$ \\ Małgorzata Kulik ${ }^{4}$ \\ Agnieszka Cyran (iD ${ }^{5}$ \\ Błażej Misiak ${ }^{5}$ \\ 'Inpatient Psychiatric Unit, Municipal \\ General Hospital, Ostrów Wielkopolski, \\ Poland; ${ }^{2}$ Department of Nervous System \\ Diseases, Wroclaw Medical University, \\ Wroclaw, Poland; ${ }^{3}$ Department of \\ Psychiatry, Pomeranian Medical \\ University, Szczecin, Poland; ${ }^{4}$ Institute of \\ Psychology, University of Szczecin, \\ Szczecin, Poland; ${ }^{5}$ Department of \\ Psychiatry, Division of Consultation \\ Psychiatry and Neuroscience, Wroclaw \\ Medical University, Wroclaw, Poland
}

Purpose: Several studies have shown that individuals with schizophrenia-spectrum disorders (SSD) employ ineffective coping styles. However, it remains unknown whether a history of adverse childhood experiences (AC Es), associated with a risk of SSD, contributes to these observations. Therefore, in this study, we aimed to investigate whether exposure to ACEs is associated with coping styles in subjects with SSD.

Patients and Methods: We recruited 127 inpatients with SSD and 56 healthy controls. Coping styles and ACEs were recorded using self-reports.

Results: Individuals with SSD had significantly higher use of using avoidance coping. A history of parental antipathy, physical and sexual abuse was significantly more frequent in subjects with SSD compared to controls. Subjects with SSD had significantly higher multiplicity and severity of ACEs. Individuals with SSD and a history of parental loss had significantly higher use of avoidance coping compared to controls with and without a history of parental loss. Other characteristics of ACEs (age at first exposure, severity and multiplicity) were not associated with using specific coping strategies.

Conclusion: These findings imply that higher use of using avoidance coping by individuals with SSD might be related to a history of parental loss.

Keywords: stress, psychosis, psychotic disorder, trauma, maltreatment

\section{Introduction}

Adverse childhood experiences (ACEs) are reported by about one-third of individuals with schizophrenia spectrum disorders (SSD). ${ }^{1}$ There is convincing evidence that ACEs increase a risk of SSD, and are related to clinical expression of SSD. ${ }^{2,3}$ Indeed, individuals with SSD and positive history of ACEs tend to show higher levels of psychotic symptoms, ${ }^{4}$ greater cognitive deficits, ${ }^{5}$ worse response to antipsychotic treatment ${ }^{6}$ and greater functional impairment. ${ }^{7}$ These observations suggest that ACEs exert a long-term impact on psychological processes that lead to the development of SSD. A recent systematic review and meta-analysis showed that processes mediating the association between ACEs and a risk of SSD include dissociation, emotional dysregulation, post-traumatic stress disorder (PTSD) symptoms and negative schemata (mental constructs of meaning). ${ }^{8}$

There is evidence that ACEs may make individuals more prone to experience subsequent adversities through increased stress sensitivity and threat anticipation. ${ }^{9-11}$ These observations provide the rationale to assume that ACEs impact the use of specific coping strategies by individuals with SSD. According to the vulnerability/
Correspondence: Błażej Misiak Department of Psychiatry, Division of Consultation Psychiatry and

Neuroscience, Wroclaw Medical University, Pasteura 10 Street, Wroclaw, 50-367, Poland

Tel +48 7I 7841630

Email blazej.misiak@umed.wroc.pl 
stress model of schizophrenia, exposure to stress that exceeds individual abilities to cope and/or the use of ineffective coping may initiate a number of psychobiological processes that trigger the onset and relapse of psychosis. ${ }^{12,13}$ Coping strategies capture a variety of trait-dependent activities approached to deal with challenges driven by stressful experiences. It has been reported that individuals with SSD tend to prefer avoidance coping than adaptive coping. ${ }^{14-19}$ Lower preference of active coping strategies and the preference of dysfunctional coping have also been associated with greater severity of positive and depressive symptoms as well as cognitive impairment. ${ }^{20-22}$

However, little is known about the association between ACEs and coping strategies approached by individuals with SSD. It has been found that a history of childhood emotional and sexual abuse is associated with passive and avoidance coping in subjects with psychotic disorders and their unaffected siblings. ${ }^{23}$ Another study demonstrated that childhood sexual abuse is related to lower likelihood of positive coping in subjects at clinical high risk of

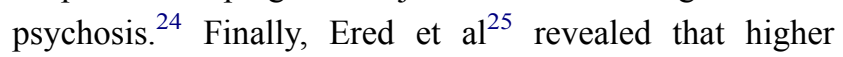
levels of maladaptive coping mediate the association between traumatic life events and psychotic-like experiences in a non-clinical sample. It should be noted that these studies did not include a comparison group of healthy controls. Therefore, it remains unknown whether the association between ACEs and coping is specific to individuals with psychosis. Moreover, other aspects of ACEs, beyond their types, such as age at first exposure, severity and multiplicity may play an important role in moderating their impact. For instance, Schalinski et $\mathrm{al}^{26}$ found that ACEs are associated with a severity of psychotic symptoms in a dose-dependent manner. The authors also revealed that neglect at the age of 10 years was the most important predictor of the severity of psychotic symptoms. Taking into account these research gaps in the field, we aimed to investigate the association between various aspects of ACEs (age at exposure, severity, multiplicity and types of ACEs) and preference of coping strategies in subjects with SSD and healthy controls.

\section{Materials and Methods}

\section{Participants}

Individuals with SSD were enrolled at three inpatient units in Poland, in the years 2016-2020 $(\mathrm{n}=127)$. The majority of them were during the treatment of psychotic relapse ( $\mathrm{n}$ $=85,66.9 \%$ ), while others were admitted for the first time
( $\mathrm{n}=42,33.1 \%$ ). Individuals with SSD were diagnosed with schizophrenia, schizoaffective disorder, schizophreniform disorder and brief psychotic disorder. Inpatients who were admitted due to psychotic relapse met the criteria of schizophrenia or schizoaffective disorder. The DSM-IV criteria assessed using the Operational Criteria for Psychotic Illness (OPCRIT) checklist were implemented to diagnose the patients. ${ }^{27}$ The majority of individuals with SSD $(n=125)$ were receiving antipsychotics with mean chlorpromazine equivalent dosage (CPZeq) of $357.7 \mathrm{mg}$ / day $(\mathrm{SD}=388.7 \mathrm{mg} /$ day $)$, while two individuals were antipsychotic-naïve on the day of assessment. The Positive and Negative Syndrome Scale (PANSS) ${ }^{28}$ was used to examine a severity of psychopathological manifestation.

There were 56 healthy controls recruited at Wroclaw Medical University (Wroclaw, Poland) through advertisements. They reported negative family history of mood and psychotic disorders in first- and second-degree relatives. The protocol of this study was approved by the Ethics Committee at Wroclaw Medical University, Wroclaw, Poland. Written informed consent was collected from all participants. The study was conducted in accordance with the Declaration of Helsinki.

\section{Assessment of ACEs}

The Childhood Experience of Care and Abuse Questionnaire (CECA.Q) was used to collect data on exposure to ACEs. ${ }^{29}$ The CECA.Q is a self-report that was developed to obtain information on the following types of ACEs before the age of 17 years:

1) Parental loss is defined as any death of mother or father before age 17 or any continuous separation from parents of at least one year.

2) Mother and father neglect is defined as a parent's lack of interest in material care, health, school activities and friendships. This category of ACEs is assessed for each biological parent or parent surrogate with whom the child lived for at least 12 months. There are 8 items scored between 1 ("no, not at all") and 5 ("yes definitely") to assess neglect of each parent. The maximum score is 40 . In case of studies with disorder outcomes, the cutoff score is 25 for mother neglect and 26 for father neglect.

3) Mother and father antipathy is defined by hostility, coldness or rejection expressed by parents or surrogate parents towards the child. This category of ACEs is assessed for each biological parent or parent surrogate with whom the child lived for at least 12 months. There 
are 8 items scored between 1 ("no, not at all") and 5 ("yes definitely") to assess antipathy expressed by each parent. The maximum score is 40 . In case of studies with disorder outcomes, the cutoff score is 28 for mother antipathy and 30 for father antipathy.

4) Physical abuse is defined as repeated hitting by parents or other older household members. This category of ACEs is recorded by the following question:

When you were a child or teenager were you ever hit repeatedly with an implement (such as a belt or stick) or punched, kicked or burnt by someone in the household?

If the answer is "yes" (score: 1), further questions regarding characteristics of ACEs need to be answered: age at onset of physical abuse, how the child was hit (belt or stick or punched/kicked; score 1 if either present), whether any injuries occurred (bruises, black eyes or broken limb; score 1 if yes) and whether the perpetrator was out of control (score 1 if yes). The maximum score is 4 . In case of studies with disorder outcomes, the cutoff score is 3 .

5) Sexual abuse is defined by physical contact or approach of a sexual nature by any adult to the child. Willing sexual contacts with peers are excluded from this definition. Sexual abuse is recorded by the following questions: "When you were a child or teenager did you ever have any unwanted sexual experiences?", "Did anyone force you or persuade you to have sexual intercourse against your wishes before age 17?" and "Can you think of any upsetting sexual experiences before age 17 with a related adult or someone in authority, eg, teacher?". Possible answers to these questions include: "yes", "no" and "unsure". "Yes" and "unsure" responses are considered positive and scored as " 1 ". In case of these responses, 8 questions regarding the severity and age at onset of sexual abuse need to be answered separately for first experience and other experiences. All of these questions (except for age at onset) have "yes" (1 point) and "no" 0 points) responses. The maximum score for the severity of each exposure is 7 . In case of studies with disorder outcomes, the cutoff for the severity score is 2 .

Additionally, the CECA.Q includes subscales for parental psychological abuse and role reversal that were not validated against interview. Therefore, these categories of ACEs were not analyzed in this study.

Apart from the analysis of specific types of ACEs, three characteristics of ACEs were also analyzed: 1) age at first exposure; 2) multiplicity and 3) severity. Age at first exposure was defined as the age when the first category of ACEs had been reported. Multiplicity was operationalized as the number of ACEs reported by each participant (parental loss, mother neglect, mother antipathy, father neglect, father antipathy, physical abuse and sexual abuse; range: 0-7). Severity was calculated for all ACEs together, except for parental loss, as the CECA.Q does not include the severity score for this category of ACEs. More specifically, we divided reported severity of exposure by the maximum severity score that can be obtained for specific category of ACEs. Next, all severity scores were summarized and divided by the number of ACEs categories $(n=6)$.

\section{Coping Strategies}

The COPE Inventory was administered to assess employment of specific coping strategies. ${ }^{30}$ It is a self-report that includes 60 statements referring to the use of specific strategies that are based on a 4-point Likert scale (1 - "I usually don't do this at all"; 2 - "I usually do this a little bit"; 3 - "I usually do this a medium amount" and "4 I usually do this a lot"). Each single coping strategy is scored based on four items. Higher scores indicate greater employment of specific coping strategies. The COPE Inventory recognizes 15 coping strategies. In the present study, we used the Polish version validated by Jurczyński and Ogińska-Bulik. ${ }^{31}$ Factor analysis of the Polish version of the COPE Inventory revealed three clusters of coping strategies (Table 1).

\section{Data Analysis}

Analyses were performed using the Statistical Package for Social Sciences, version 20 (SPSS Inc., Chicago, Illinois, USA). Bivariate comparisons were assessed using the $\chi^{2}$ test or the Mann-Whitney $U$-test, where appropriate. According to the Kolmogorov-Smirnov test, the majority of continuous variables (except for the scores of active coping and emotion-focused coping had non-normal distribution). The scores of avoidance coping were the only variable that appeared to have normal distribution after logarithmic transformation. Therefore, data analysis was based on both non-parametric and parametric tests. Correlations with the scores of coping strategies were tested using the linear regression analysis. The analysis of co-variance (ANCOVA) was performed to explore the effects of group (SSD vs controls) and types of ACEs on the scores of coping strategies. Age and sex were added as co-variates in linear regression analyses and ANCOVA. In case of significant interactions between group (SSD vs 
Table I The COPE Inventory Clusters of Coping Strategies

\begin{tabular}{|c|c|c|}
\hline Active Coping (Score Range: $20-80$ ) & $\begin{array}{l}\text { Avoidance Coping (Score Range: } \\
\text { 24-96) }\end{array}$ & $\begin{array}{l}\text { Emotion-Focused Coping (Score Range: 16- } \\
\text { 64) }\end{array}$ \\
\hline $\begin{array}{l}\text {-Active coping (items: } 5,25,47,58 \text { ) } \\
\text {-Planning (items: } 19,32,39,56 \text { ) } \\
\text {-Suppression of competing activities (items: I5, } \\
33,42,55 \text { ) } \\
\text {-Positive reinterpretation and growth (items: I, } \\
29,38,59 \text { ) } \\
\text {-Restraint (items: 10, 22, 4I, 49) }\end{array}$ & $\begin{array}{l}\text {-Acceptance (items: I3, 2I, 44, 54) } \\
\text {-Denial (items: 6, 27, 40, 57) } \\
\text {-Behavioral disengagement (items: 9, 24, } \\
37,51 \text { ) } \\
\text {-Mental disengagement }(2,16,31,43 \text { ) } \\
\text {-Substance use (items: } 12,26,35,53 \text { ) } \\
\text {-Humor (items: } 8,20,36,50)\end{array}$ & $\begin{array}{l}\text {-Seeking of emotional social support (items: II, 23, } \\
34,52 \text { ) } \\
\text {-Seeking of instrumental social support (items: } 4 \text {, } \\
\text { I4, 30, 45) } \\
\text {-Turning to religion (items } 7,18,48,60 \text { ) } \\
\text {-Focus on and venting of emotions (items } 3,17,28 \text {, } \\
46 \text { ) }\end{array}$ \\
\hline
\end{tabular}

controls) and a history of ACEs, post-hoc comparisons were performed using the Games-Howell test. Due to the use of multiple tests $(n=110)$, the Benjamini-Hochberg correction with the $25 \%$ false discovery rate was applied. The level of significance was set at $\mathrm{p} \leq 0.009$ after applying the correction for multiple testing.

\section{Results}

Individuals with SSD and healthy controls did not differ significantly in terms of age and sex (Table 2). As expected, the number of education years was significantly lower in subjects with SSD compared to healthy controls. The group of participants with SSD was significantly more likely to report a history of parental antipathy, physical abuse and sexual abuse in comparison with healthy controls. Multiplicity and severity of ACEs were significantly higher in subjects with SSD. No significant between-group differences were found with respect to the rates of parental loss and parental neglect as well as age at first exposure. The use of avoidance coping was significantly higher in subjects with SSD compared to healthy controls, after adjustment for age and sex (Figure 1).

No significant correlations of coping strategies with continuous characteristics of ACEs were found (age at first exposure, severity and multiplicity) neither in individuals with SSD nor in healthy controls (Table 3). In turn, associations between a history of specific ACEs and coping strategies are presented in Table 4. There were significant main effects of group (SSD vs healthy controls) on the use of avoidance coping in almost all ANCOVA models (except for the one testing for the effects of sexual abuse). Importantly, in the model testing for the effects of parental loss, significant effects of interactions between group (SSD vs healthy controls) and ACEs on the use of

Table 2 General Characteristics of the Sample

\begin{tabular}{|c|c|c|c|}
\hline & SSD, $n=127$ & Controls, $n=56$ & Statistics \\
\hline Age, years & $39.1 \pm 13.8$ & $38.3 \pm 6.8$ & $U=3366.5, p=0.566$ \\
\hline Gender, males (\%) & $61(48.0)$ & $24(42.8)$ & $\chi^{2}=0.4, p=0.518$ \\
\hline Education, years & $13.2 \pm 2.8$ & $16.0 \pm 2.4$ & $U=889.5, p<0.001$ \\
\hline Parental loss, n(\%) & $38(29.9)$ & $12(21.4)$ & $\chi^{2}=1.5, p=0.223$ \\
\hline Parental antipathy, n(\%) & $68(53.5)$ & $16(28.6)$ & $\chi^{2}=10.1, p=0.002$ \\
\hline Parental neglect, n(\%) & $41(32.3)$ & $16(28.6)$ & $\chi^{2}=0.3, p=0.594$ \\
\hline Physical abuse, n(\%) & $55(43.3)$ & $13(23.2)$ & $\chi^{2}=6.9, p=0.009$ \\
\hline Sexual abuse, n(\%) & $29(22.8)$ & $3(5.4)$ & $\chi^{2}=8.3, p=0.004$ \\
\hline Age at first exposure & $9.5 \pm 4.6$ & $9.0 \pm 4.6$ & $U=1037.5, p=0.616$ \\
\hline Multiplicity & $2.3 \pm 1.8$ & $1.1 \pm 1.3$ & $U=4940.5, p<0.00 I$ \\
\hline Severity & $0.4 \pm 0.3$ & $0.3 \pm 0.4$ & $U=4965.5, p<0.001$ \\
\hline PANSS-P & $19.9 \pm 10.0$ & - & - \\
\hline PANSS-N & $24.4 \pm 9.8$ & - & - \\
\hline First admission, n (\%) & $42(33.1)$ & - & - \\
\hline CPZeq, mg/day & $357.7 \pm 388.7$ & - & - \\
\hline
\end{tabular}

Note: Significant differences $(p \leq 0.009)$ were marked with bold characters.

Abbreviations: CECA.Q, the Childhood Experience of Care and Abuse Questionnaire; CPZeq, chlorpromazine equivalent dosage; MADRS, the Montgomery-Asberg Depression Rating Scale; PANSS, the Positive and Negative Syndrome Scale; SSD, schizophrenia spectrum disorders; YMRS, the Young Mania Rating Scale. 


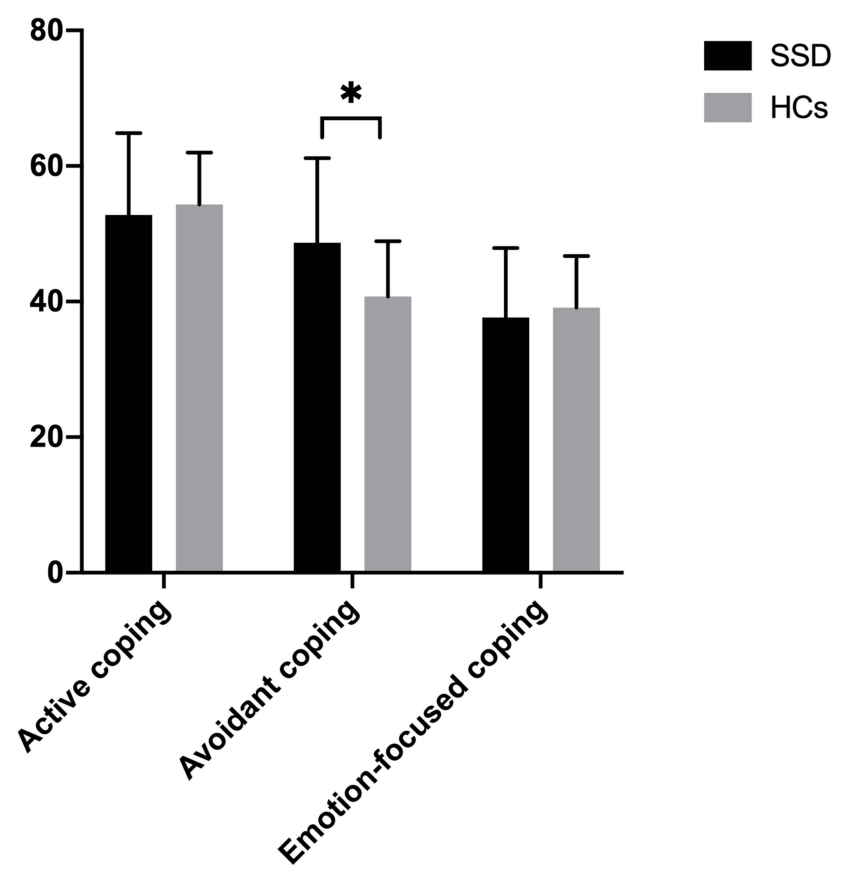

Figure I Coping strategies in individuals with SSD and healthy controls. Mean values are shown. Error bars represent standard deviation. *The use of avoidance coping was significantly higher in subjects with SSD compared to healthy controls after adjustment for age and sex $\left[F(1 / 82)=17.096, \eta_{p}{ }^{2}=0.123, p<0.001 ; 48.7 \pm\right.$ 12.5 vs $40.7 \pm 8.2$, respectively]. No significant differences between individuals with SSD and healthy controls with respect to using active coping $\left[\mathrm{F}(1182)=1.099, \eta_{\mathrm{p}}{ }^{2}=\right.$ $0.009, p=0.297 ; 52.8 \pm 12.1$ vs $54.3 \pm 7.6$, respectively) and emotion-focused coping $\left[F(1182)=0.041, \eta_{p}{ }^{2}<0.001, p=0.840 ; 37.6 \pm 10.3\right.$ vs $39.1 \pm 7.6$, respectively]

avoidance coping were found. Post-hoc analyses revealed that the use of avoidance coping was significantly higher only in individuals with SSD and a history of parental compared to healthy controls with and without a history of parental loss (Figure 2).

\section{Discussion}

The present study confirms previous findings that individuals with SSD tend to rely on avoidance coping. ${ }^{32,33}$ More interestingly, we found significantly higher use of avoidance coping only in subjects with SSD and a history of parental loss, compared to healthy controls with and without a history of parental loss. However, we did not find any significant associations of other characteristics of ACEs (age at first exposure, multiplicity and severity) with the use of coping strategies.

Coping refers to a range of cognitive and behavioral strategies that are used to meet the demands driven by stressful situations. ${ }^{34}$ These processes are activated by appraisals of external and internal demands against individual resources. ${ }^{35}$ Appraisals can be largely influenced by lifetime experiences. ${ }^{35}$ Among them, there is an important role of parental support that enhances the development of more adaptive coping strategies. ${ }^{36}$ Early parental loss may exceed individual cognitive capacity to understand and cope with this experience as well as it may disrupt further development of coping strategies. ${ }^{37}$ Adults who experienced early parental loss have been shown to report more substance use, behavioral disengagement and emotional eating. ${ }^{38}$

Our findings are also consistent with those reported by Tait et $\mathrm{al}^{39}$ in subjects during recovery from psychosis. The authors demonstrated that participants with sealingover recovery styles report lower levels of parental care during childhood. A meta-analysis of eight studies revealed that parental loss is related to 1.70 -fold higher risk of developing psychosis. ${ }^{3}$ More recently, Misra et al ${ }^{40}$ confirmed these results in a large, six-country case-control study (OR: 1.54, 95\% CI: 1.18-4.37). However, the authors noticed that single experience of early parental death is rather insufficient to cause psychosis, and it is likely that certain antecedents and consequences of parental loss might be causative. First, a risk of parental loss and its consequences might be higher in socially disadvantaged populations. Examples of consequences might include quality of care and support after parental loss, engagement in risky behaviors (eg, substance use), subsequent stressors and changes in economic status. ${ }^{35}$

Table 3 Bivariate Correlations Between Coping Strategies and Symptomatic Manifestation

\begin{tabular}{|c|c|c|c|c|}
\hline & Group & Active Coping & Avoidance Coping & Emotion-Focused Coping \\
\hline Age at first exposure & $\begin{array}{l}\text { SSD } \\
\text { Controls }\end{array}$ & $\begin{array}{l}B=-0.657, p=0.241 \\
B=0.400, p=0.403\end{array}$ & $\begin{array}{l}B=-0.016, p=0.046 \\
B=0.001, p=0.747\end{array}$ & $\begin{array}{l}B=-0.390, p=0.419 \\
B=0.773, p=0.076\end{array}$ \\
\hline Multiplicity & $\begin{array}{l}\text { SSD } \\
\text { Controls }\end{array}$ & $\begin{array}{l}B=0.648, p=0.454 \\
B=0.390, p=0.620\end{array}$ & $\begin{array}{l}B=0.011, p=0.076 \\
B=-0.008, p=0.098\end{array}$ & $\begin{array}{l}B=0.549, P=0.447 \\
B=-0.462, p=0.562\end{array}$ \\
\hline Severity & $\begin{array}{l}\text { SSD } \\
\text { Controls }\end{array}$ & $\begin{array}{l}B=-2.941, P=0.494 \\
B=-2.315, p=0.413\end{array}$ & $\begin{array}{l}B=0.033, p=0.367 \\
B=-0.006, p=0.862\end{array}$ & $\begin{array}{l}B=-2.730, p=0.447 \\
B=1.668, p=0.561\end{array}$ \\
\hline
\end{tabular}




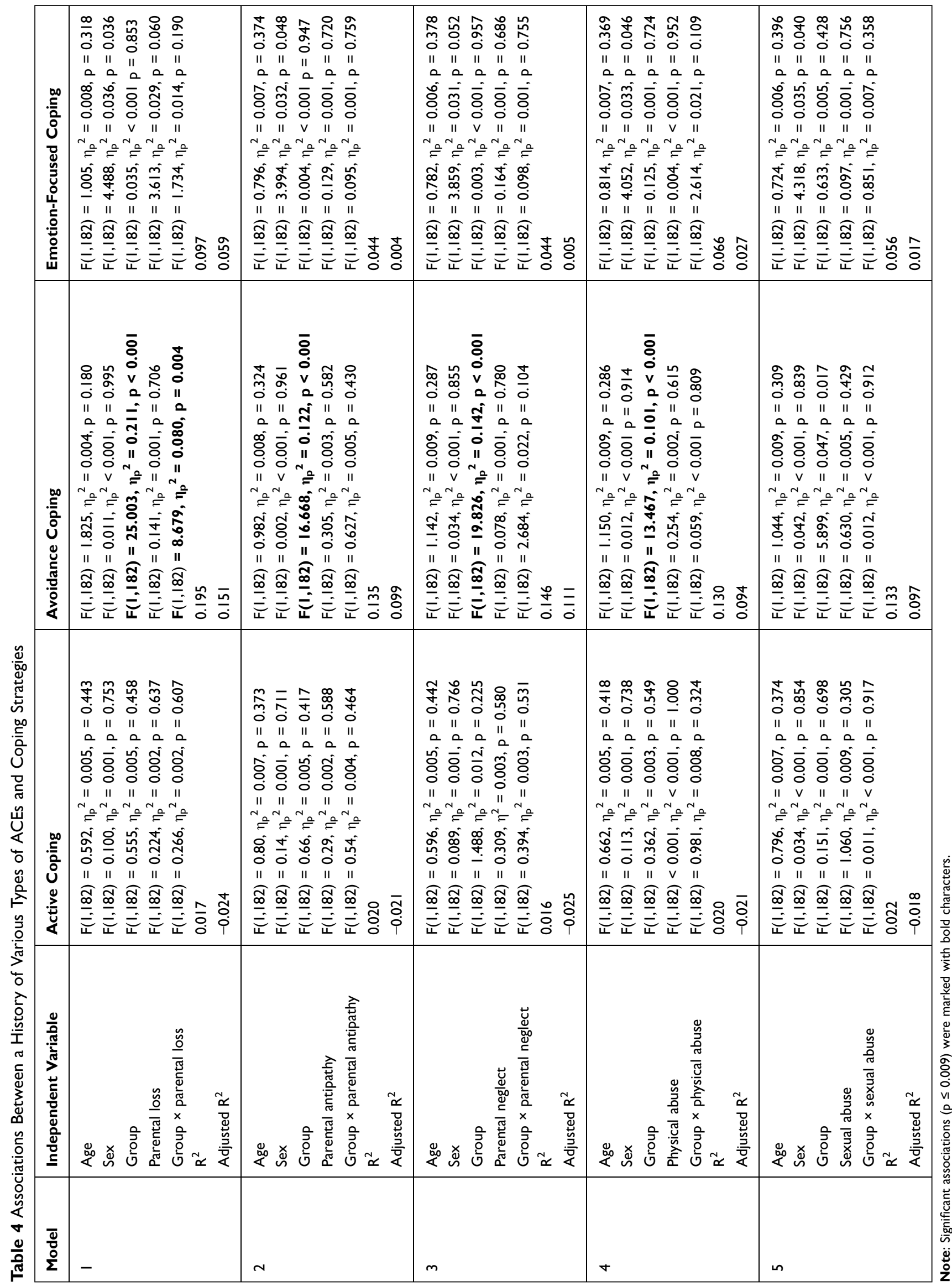




\section{Post hoc comparisons:}

SSD, parental loss(+) vs. SSD, parental loss(-): $p=0.048$ Controls, parental loss $(+)$ vs. Controls, parental loss $(-): p=0.078$ SSD, parental loss(+) vs. Controls, parental loss(+): $\mathbf{p}<\mathbf{0 . 0 0 1}$ SSD, parental loss(-) vs. Controls, parental loss $(-): p=0.201$ SSD, parental loss(+) vs. Controls, parental loss $(-): \mathbf{p}=\mathbf{0 . 0 0 1}$ SSD, parental loss(-) vs. Controls, parental loss $(+): p=0.051$

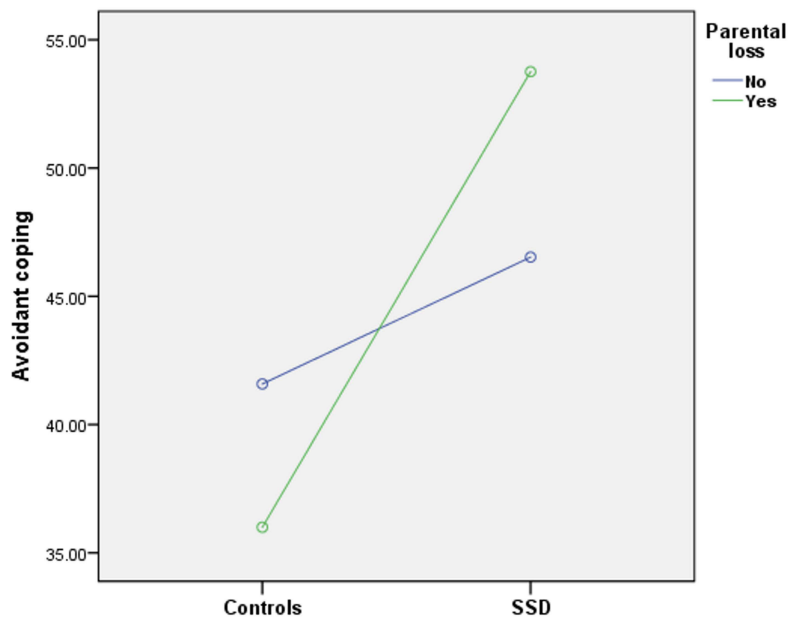

Figure 2 Effects of parental loss on avoidance coping in individuals with SSD and healthy controls. Significant differences $(p \leq 0.009)$ were marked with bold characters.

Abbreviations: parental loss(+), participants with a history of parental loss; parental loss(-), participants without a history of parental loss.

The present study has important limitations requiring further comments. First, the sample size was not large. This might explain as to why we did not find significantly higher rates of parental loss in individuals with SSD compared to healthy controls. Additionally, we did not perform a more detailed analysis of parental loss. It is likely that the impact of this adversity is related to several characteristics, eg, the number of parents lost, causes and circumstances of death and age at parental loss. Another important point is that the percentage of variance explained by the ANCOVA models was relatively low, and thus it is likely that other factors, not recorded by the present study, also impact coping strategies. Moreover, we did not measure potential antecedents and consequences of ACEs. Therefore, this study does not provide mechanistic insights into the association between parental loss and coping styles. Finally, it should be noted that assessment of ACEs was based on self-reports, and the recall bias should be taken into consideration.

\section{Conclusion}

In conclusion, this study indicates that the use of avoidance coping is higher among individuals with SSD compared to healthy controls. This phenomenon might be associated with parental loss. The present findings have certain research and clinical implications. Future studies in this field need to provide a closer look at the role of antecedents and consequences of parental loss in shaping individual coping strategies. This might be achieved by detailed analysis of socioeconomic status, parental bonding and attachment styles as well as engagement in risky health behaviors over time. Given that coping styles have previously been shown to impact clinical manifestation of SSD, it is important to focus psychological interventions on strengthening adaptive coping in this population. However, these interventions need to take into consideration the impact of ACEs, especially parental loss.

\section{Acknowledgment}

This study was funded by the Iuventus Plus grant awarded by the Ministry of Science and Higher Educations (IP2015 052474).

\section{Disclosure}

Professor Błażej Misiak report grants and personal fees from Ministry of Science and Higher Education, during the conduct of the study. The authors report no other conflicts of interest in this work.

\section{References}

1. Bonoldi I, Simeone E, Rocchetti M, et al. Prevalence of self-reported childhood abuse in psychosis: a meta-analysis of retrospective studies. Psychiatry Res. 2013;210(1):8-15. doi:10.1016/j.psychres.2013.05.003

2. Misiak B, Krefft M, Bielawski T, Moustafa AA, Sąsiadek MM, Frydecka D. Toward a unified theory of childhood trauma and psychosis: a comprehensive review of epidemiological, clinical, neuropsychological and biological findings. Neurosci Biobehav Rev. 2017;75:393-406. doi:10.1016/j.neubiorev.2017.02.015

3. Varese F, Smeets F, Drukker M, et al. Childhood adversities increase the risk of psychosis: a meta-analysis of patient-control, prospective-and cross-sectional cohort studies. Schizophr Bull. 2012;38(4):661-671. doi:10.1093/schbul/sbs050

4. Bailey T, Alvarez-Jimenez M, Garcia-Sanchez AM, Hulbert C, Barlow E, Bendall S. Childhood trauma is associated with severity of hallucinations and delusions in psychotic disorders: a systematic review and meta-analysis. Schizophr Bull. 2018;44(5):1111-1122.

5. Vargas T, Lam PH, Azis M, Osborne KJ, Lieberman A, Mittal VA. Childhood trauma and neurocognition in adults with psychotic disorders: a systematic review and meta-analysis. Schizophr Bull. 2019;45 (6):1195-1208. doi:10.1093/schbul/sby150

6. Misiak B, Frydecka D. A history of childhood trauma and response to treatment with antipsychotics in first-episode schizophrenia patients. J Nerv Ment Dis. 2016;204(10):787-792. doi:10.1097/NMD.0000000000000567

7. Palmier-Claus J, Berry K, Darrell-Berry H, et al. Childhood adversity and social functioning in psychosis: exploring clinical and cognitive mediators. Psychiatry Res. 2016;238:25-32. doi:10.1016/j.psychres.2016.02.004

8. Bloomfield MAP, Chang T, Woodl MJ, et al. Psychological processes mediating the association between developmental trauma and specific psychotic symptoms in adults: a systematic review and meta-analysis. World Psychiatry. 2021;20(1):107-123. doi:10.1002/wps.20841 
9. Myin-Germeys I, Van Os J, Schwartz JE, Stone AA, Delespaul PA. Emotional reactivity to daily life stress in psychosis. Arch Gen Psychiatry. 2001;58(12):1137-1144. doi:10.1001/archpsyc.58.12.1137

10. Howes OD, Murray RM. Schizophrenia: an integrated sociodevelopmental-cognitive model. Lancet. 2014;383 (9929):1677-1687. doi:10.1016/S0140-6736(13)62036-X

11. Reininghaus U, Gayer-Anderson C, Valmaggia L, et al. Psychological processes underlying the association between childhood trauma and psychosis in daily life: an experience sampling study. Psychol Med. 2016;46(13):2799-2813. doi:10.1017/S003329171600146X

12. Nuechterlein KH, Dawson ME. A heuristic vulnerability/stress model of schizophrenic episodes. Schizophr Bull. 1984;10(2):300-312. doi:10.1093/schbul/10.2.300

13. Nuechterlein KH, Dawson ME, Ventura J, et al. The vulnerability/ stress model of schizophrenic relapse: a longitudinal study. Acta Psychiatr Scand. 1994;89(s382):58-64. doi:10.1111/j.16000447.1994.tb05867.x

14. Allott KA, Rapado-Castro M, Proffitt TM, et al. The impact of neuropsychological functioning and coping style on perceived stress in individuals with first-episode psychosis and healthy controls. Psychiatry Res. 2015;226(1):128-135. doi:10.1016/j. psychres.2014.12.032

15. Corrigan PW, Toomey R. Interpersonal problem solving and information processing in schizophrenia. Schizophr Bull. 1995;21 (3):395-403. doi:10.1093/schbul/21.3.395

16. Horan WP, Ventura J, Mintz J, et al. Stress and coping responses to a natural disaster in people with schizophrenia. Psychiatry Res. 2007;151(1-2):77-86. doi:10.1016/j.psychres.2006.10.009

17. Lysaker PH, Davis LW, Lightfoot J, Hunter N, Stasburger A. Association of neurocognition, anxiety, positive and negative symptoms with coping preference in schizophrenia spectrum disorders. Schizophr Res. 2005;80(2-3):163-171. doi:10.1016/j. schres.2005.07.005

18. Ritsner MS, Gibel A, Ponizovsky AM, Shinkarenko E, Ratner Y, Kurs R. Coping patterns as a valid presentation of the diversity of coping responses in schizophrenia patients. Psychiatry Res. 2006;144 (2-3):139-152. doi:10.1016/j.psychres.2005.09.017

19. Ventura J, Nuechterlein KH, Subotnik KL, Green MF, Gitlin MJ. Self-efficacy and neurocognition may be related to coping responses in recent-onset schizophrenia. Schizophr Res. 2004;69(2-3):343-352. doi:10.1016/j.schres.2003.09.002

20. Meyer B. Coping with severe mental illness: relations of the brief COPE with symptoms, functioning, and well-being. J Psychopathol Behav Assess. 2001;23(4):265-277. doi:10.1023/A:1012731520781

21. Moritz S, Lüdtke T, Westermann S, Hermeneit J, Watroba J, Lincoln TM. Dysfunctional coping with stress in psychosis. An investigation with the Maladaptive and Adaptive Coping Styles (MAX) questionnaire. Schizophr Res. 2016;175(1-3):129-135. doi:10.1016/j.schres.2016.04.025

22. Stramecki F, Kotowicz K, Piotrowski P, et al. Coping styles and symptomatic manifestation of first-episode psychosis: focus on cognitive performance. Psychiatry Res. 2019;272:246-251. doi:10.1016/ j.psychres.2018.12.083

23. Renkema TC, de Haan L, Schirmbeck F, et al. Childhood trauma and coping in patients with psychotic disorders and obsessive-compulsive symptoms and in un-affected siblings. Child Abus Negl. 2020;99:104243. doi:10.1016/j.chiabu.2019.104243
24. Schmidt SJ, Schultze-Lutter F, Bendall S, et al. Mediators linking childhood adversities and trauma to suicidality in individuals at risk for psychosis. Front Psychiatry. 2017;8:242. doi:10.3389/ fpsyt.2017.00242

25. Ered A, Gibson LE, Maxwell SD, Cooper S, Ellman LM. Coping as a mediator of stress and psychotic-like experiences. Eur Psychiatry. 2017;43:9-13. doi:10.1016/j.eurpsy.2017.01.327

26. Schalinski I, Breinlinger S, Hirt V, Teicher MH, Odenwald M, Rockstroh B. Environmental adversities and psychotic symptoms: the impact of timing of trauma, abuse, and neglect. Schizophr Res. 2019;205:4-9. doi:10.1016/j.schres.2017.10.034

27. McGuffin P. A polydiagnostic application of operational criteria in studies of psychotic illness. Arch Gen Psychiatry. 1991;48(8):764. doi:10.1001/archpsyc.1991.01810320088015

28. Kay SR, Fiszbein A, Opler LA. The positive and negative syndrome scale (PANSS) for schizophrenia. Schizophr Bull. 1987;13 (2):261-276. doi:10.1093/schbul/13.2.261

29. Bifulco A, Bernazzani O, Moran PM, Jacobs C. The childhood experience of care and abuse questionnaire (CECA.Q): validation in a community series. Br J Clin Psychol. 2005;44(Pt 4):563-581. doi:10.1348/014466505X35344

30. Carver CS, Scheier MF, Weintraub KJ. Assessing coping strategies: a theoretically based approach. J Pers Soc Psychol. 1989;56 (2):267-283. doi:10.1037/0022-3514.56.2.267

31. Jurczyński Z, Ogińska-Bulik N. Narzędzia Pomiaru Stresu $i$ Radzenia Sobie Ze Stresem. Psychological Test Laboratory of the Polish Psychological Association; 2012.

32. MacAulay R, Cohen AS. Affecting coping: does neurocognition predict approach and avoidant coping strategies within schizophrenia spectrum disorders? Psychiatry Res. 2013;209(2):136-141. doi:10.1016/j.psychres.2013.04.004

33. Van Den Bosch RJ, Rombouts RP. Coping and cognition in schizophrenia and depression. Compr Psychiatry. 1997;38(6):341-344. doi:10.1016/S0010-440X(97)90930-5

34. Folkman S, Moskowitz JT. Coping: pitfalls and promise. Ann Rev Psychol. 2004;55(1):745-774. doi:10.1146/annurev. psych.55.090902.141456

35. Lazarus RS, Folkman S. Stress, Appraisal, and Coping. New York: Springer; 1984.

36. Zimmer-Gembeck MJ, Skinner EA. Review: the development of coping across childhood and adolescence: an integrative review and critique of research. Int J Behav Dev. 2011;35(1):1-17. doi:10.1177/ 0165025410384923

37. Webb NB. The child and death. In: Webb NB, editor. Helping Bereaved Children: A Handbook for Practitioners. 3rd ed. New York: Guilford Press; 2010:3-21.

38. Høeg BL, Appel CW, Von heymann-horan AB, et al. Maladaptive coping in adults who have experienced early parental loss and grief counseling. J Health Psychol. 2017;22(14):1851-1861. doi:10.1177/ 1359105316638550

39. Tait L, Birchwood M, Trower P. Adapting to the challenge of psychosis: personal resilience and the use of sealing-over (avoidant) coping strategies. $\mathrm{Br} \quad J \quad$ Psychiatry. 2004;185(5):410-415. doi:10.1192/bjp.185.5.410

40. Misra S, Gelaye B, Koenen KC, et al. Early parental death and risk of psychosis in offspring: a six-country case-control study. J Clin Med. 2019;8(7):1081. doi:10.3390/jcm8071081 


\section{Publish your work in this journal}

Psychology Research and Behavior Management is an international, peer-reviewed, open access journal focusing on the science of psychology and its application in behavior management to develop improved outcomes in the clinical, educational, sports and business arenas. Specific topics covered in the journal include: Neuroscience, memory and decision making; Behavior modification and management; Clinical

applications; Business and sports performance management; Social and developmental studies; Animal studies. The manuscript management system is completely online and includes a very quick and fair peer-review system, which is all easy to use. Visit http://www. dovepress.com/testimonials.php to read real quotes from published authors. 